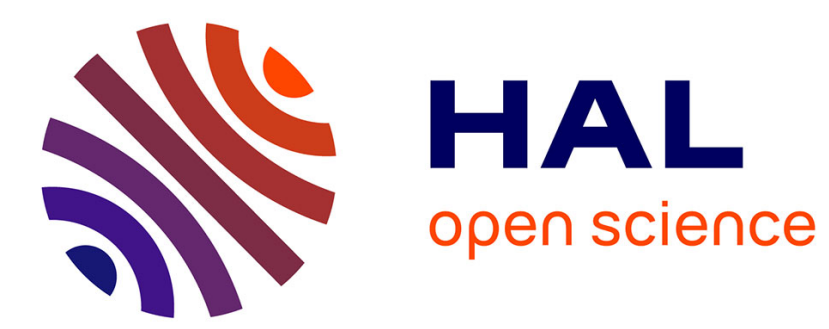

\title{
Estimating regional-level input demand for french agriculture using a Translog production function
}

\author{
Francois Bonnieux
}

\section{To cite this version:}

Francois Bonnieux. Estimating regional-level input demand for french agriculture using a Translog production function. European Review of Agricultural Economics, 1989, 16-2, pp.229-241. hal01595670

\author{
HAL Id: hal-01595670 \\ https://hal.science/hal-01595670
}

Submitted on 26 Sep 2017

HAL is a multi-disciplinary open access archive for the deposit and dissemination of scientific research documents, whether they are published or not. The documents may come from teaching and research institutions in France or abroad, or from public or private research centers.
L'archive ouverte pluridisciplinaire HAL, est destinée au dépôt et à la diffusion de documents scientifiques de niveau recherche, publiés ou non, émanant des établissements d'enseignement et de recherche français ou étrangers, des laboratoires publics ou privés.

\section{(ㅇ)(1) $\$$}

Distributed under a Creative Commons Attribution - NonCommercial - NoDerivatives| 4.0 


\title{
Estimating regional-level input demand for French agriculture using a translog production function
}

\author{
FRANCOIS BONNIEUX * \\ INRA, Economio et Saciologio Rurales, Rennes, France
}

\section{Summary}

The purpose of this paper is to estimate a system of input demand responses for French agriculture, supposed to be in static equilibrium with respects to all inputs. A translog production function with regional dummies is specified.

The adjusted model is well-behaved for a large region in the input space and therefore allows general conclusions. First input separability is rejected. The technical separability of materials for all primary inputs is quite large. Moreover there is a substitutability relationship (except for intensive livestock farming) between labour and capital, land and labour but capital and land are complements.

\section{Introduction}

In order to measure the impact of price policies at regional level, it is necessary to have estimates of elasticities for inputs and outputs. The purpose of this paper is to estimate a system of factor demand responses for French agriculture on a regional basis. The model is intended to quantify not only the input responses but also the more basic structural relations underlying market responses such as input substitutability or complementarity. A second issue deals with the question of separability. Here, the use of the value-added concept which implicitly assumes that the technology is separable in the primary inputs and in the intermediate inputs so that a consistent aggregate of primary inputs exists, will be questioned.

During the last decade, the dual approach has become popular among agricultural economists, but few contributions have been devoted to European countries, some recent papers have to be quoted: Boyle (1981), Higgins

- I am indebted to the referees of the review, H. Guyomard and P. Rainelli for their helpful comments. 
(1986) both concerning Irish agriculture, Mergos (1987), Mergos and Yotopoulos (1988) for Greece and Guyomard (1988) for France. There are no regional time series available to study the long-term behaviour of French agriculture. Therefore, regional cross-sectional data concerning the years 1979-81 have been used. Because regional prices are so highly correlated for most inputs it has not been possible to use a dual approach. In this paper, a production function taking into account heterogeneity among regions has been specified. The estimation process uses input levels as explanatory variables. This is a theoretical limitation of the primal approach but it yields a set of Hicksian elasticities which are consistent with figures published elsewhere.

The agricultural sector is assumed to be in static equilibrium with respect to all inputs. The following four input categories were employed in this study: materials, capital, land and labour. A breaking-down of labour in order to distinguish hired and self-employed labour has also been considered. It provides an insight into this specific component which is often viewed as a single input. We do not regard land as a fixed factor for the farm sector because in the long run there is some room, through plot consolidation, drainage and irrigation, to improve land services. Moreover, there is a decrease in total acreage in response to urbanization, the development of public facilities and set-aside acreage policies.

The plan of this paper is as follows. Section 2 describes the econometric model. Section 3 is devoted to a brief presentation of the data and a discussion of the statistical results. A set of interrelated input demand functions are given together with comments on input separability.

\section{Model specification}

The translog functional form is selected to represent a twice continuously differentiable regional production function. As a flexible form, it has the advantage of not imposing arbitrary restrictions on the substitution elasticities. Moreover, there is an extreme heterogeneity among regions and therefore farmers' response is expected to differ substantially between areas. In order to test this important hypothesis regional dummies are introduced in the model. Regions are classified into categories corresponding to various types of farming.

A translog production function describing the relation between total output $Y$ and input services $X_{i}$ may be written:

$$
\begin{aligned}
\operatorname{Ln} Y=a_{0}+\sum_{i, k}\left(a_{i}+a_{i k} D_{k}\right) \operatorname{Ln} X_{i}+\frac{1}{2} \sum_{i, j} b_{i j} \operatorname{Ln} X_{i} \operatorname{Ln} X_{J} \\
\qquad i, j=1, \ldots, I ; k=1, \ldots, K-1,
\end{aligned}
$$


where $L n$ stands for the natural logarithm and $D_{K}$ denotes the dummy corresponding to category of regions $k$.

The parameter $a_{0}$ represents the state of technical knowledge and $a_{i}, a_{i k}, b_{i j}$. are technologically determined parameters. If one adopts the maintained hypothesis that (1) is subject to constant returns to scale, the following restrictions hold:

$$
\sum_{i} a_{i}=1 ; \sum_{i} a_{i k}=0, \quad k=1 \ldots K-1 ; \sum_{i} b_{i j}=\sum_{j} b_{i j}=0
$$

$$
i, j=1, \ldots, I \text {. }
$$

So there are $(I-1) K$ independent $a_{i}$ and $a_{i k}$ parameters plus $I(I-1) / 2$ independent $b_{i j}$ parameters. ${ }^{1}$

Assuming profit maximizing behaviour, exogenous prices of output and inputs, and differentiating the translog function (1) we find the system of input share equations:

$$
M_{i}=a_{i}+\sum_{k} a_{i k} D_{k}+\sum_{j} b_{i j} \operatorname{Ln} X_{j}, \quad i=1, \ldots, I .
$$

The $M_{t}(i=1, \ldots, I)$ are the cost shares of the inputs $(1, \ldots, I)$ in the output and they add up to unity.

The translog function is not well-behaved globally. In fact, when at least one $b_{i j}$ is different from zero there are input values such that neither monotonocity nor convexity is satisfied (Berndt and Christensen, 1973a). Monotonocity requires that marginal products are positive. Since the output and inputs are positive, it is equivalent with $\boldsymbol{M}_{i}$ positive. Convexity is satisfied if the bordered Hessian matrix of first and second partial derivatives of the production function is negative definite. Using Diewert's results (1974: 108-114), this can be replaced by a similar condition on the matrix of Allen substitution elasticities. The latter one has to be negative semi-definite to ensure convexity. Therefore, for any value of parameters and inputs monotonocity and convexity conditions can easily be checked in order to divide the input space between economic and uneconomic regions.

All parameters that are required to estimate the substitution elasticities and the input demand equations are provided by the system of share equations (3). We propose therefore to estimate this system instead of the production function (1) in order to avoid estimation difficulties caused by multicollinearity.

Deviations from profit maximization behaviour are represented by a random error term added to each share equation. As the cost shares sum to one, the variance-covariance matrix of the error terms is singular and one of the share equation must be dropped to make estimation possible. Maximumlikelihood estimates are, of course, independent from the equations which are selected. We used the full-information-maximum-likelihood procedure. It yields consistent and asymptotically efficient estimates. All of the param- 
eters of the excluded equations are obtained using conditions (2) and have these desirable properties because they are linear combinations of the former estimates.

Price elasticities of input demands can be derived for points in the input space where the adjusted production function is well-behaved. The elasticity of the demand for $X_{i}$ relative to the price of $X_{j}$ is equal to:

$$
e_{i j}=s_{t,} M_{j} \quad i, j=1, \ldots, I \text {, }
$$

where $s_{i j}$ is the Allen elasticity of substitution between inputs $X_{i}$ and $X_{j}$.

This relation is easily verified using the dual cost function (Diewert, 1974: 114 ) and it is clear that these elasticities are of Hicksian type. The derivation of Allen elasticities is tedious for the primal case and it is given in an annex.

Since $e_{i j}$ and $s_{i j}$ have the same sign, Allen elasticities are used to classify inputs as substitutes or complements. If $s_{i j}$ is positive the inputs $X_{i}$ and $X_{j}$ are substitutes. If it is negative they are complements. Let us be more specific and consider the effect of an increase of the price of input $j$ upon the cost share $M_{i}$. It will increase if $s_{l j}$ is higher than unity, otherwise it will decrease. So, we will distinguish between strong substitutability $\left(s_{i j}>1\right)$ and weak substitutability $\left(0<s_{i j}<1\right)$.

Allen elasticities give a straightforward means to study separability (Berndt and Christensen, 1973b). Separability has strong implications since it justifies optimization by stages and therefore allows decentraliation in decision-making. We will consider below a local test in the input space to establish weak separability by category of regions.

\section{Data and estimation}

\subsection{Data}

The required data are cost shares and levels of inputs. All of them are included in an agricultural data bank which gathered regional data from 1959 to 1983. France is divided into 89 regions which correspond to the French 'departements' except for the Paris Region which is broken down into two units instead of eight 'départements'.

Regional accounts ('Comptes départementaux') are published annually by the Ministry of Agriculture and are consistent with national accounts. In order to eliminate random variations due to various reasons as for instance weather conditions, three year averages (1979-81) are calculated. These accounts provide the information needed to calculate total output, the cost of materials, hired labour and rented land. As a balance they consider a concept of gross agricultural income that we had to split into different components in order to obtain the cost of remaining land, capital and self employed labour. Using data from the 1979-80 Agricultural Census, a rental 
price of land was obtained by region and applied to land owned by farm operators. Depreciation for machinery and buildings (excluding residential structures) for various years including 1980, is regionally available (SCEES, 1981). This information is consistent with national figures and has been used to assess the cost of capital. The estimation of the cost share of self employed labour relies upon the assumption that output is totally distributed among inputs. Therefore, it is obtained directly since the cost shares of the other factors are known.

Except for materials input services are expressed in physical units. Capital input is obtained as a weighted average of machinery power and building area for different categories of these assets. Land input is measured in acreage equivalent of arable land. As for labour the number of labour units is considered. All quantities are centered around the geometric mean.

Classification of regions by type of farming (Table 1) is obtained as the result of a hierarchical analysis. The data input includes agricultural outputs and materials, 13 and 7 categories were respectively considered. Seven classes of region have been determined and regional dummies were defined straightforward. Therefore, this classification captures the differences of regional production conditions. Within category differences are far smaller than between categories (Bonnieux, 1986: 253-254).

\subsection{Empirical results}

The structural parameters derived by estimation of the cost share equations (3) with the full-information maximum likelihood method, are reported in Tables 2 and 3. The number of independent parameters equals 27 and the log-likelihood reaches 499.9. Coefficients of log-quantities are the same for every category of regions, whereas the intercepts vary according to the hypothesis of regional heterogeneity.

Table 1. Classification of regions by type of farming

\begin{tabular}{ll}
\hline type of farming & $\begin{array}{l}\text { number of } \\
\text { regions }\end{array}$ \\
\hline crop farming (mainly field crops and cereals) & 19 \\
market gardening and orchards (horticulture and fruit) & 10 \\
vineyards & 12 \\
mixed farming (crops and livestock) & 17 \\
intensive livestock farming (mainly pigs and poultry) & 3 \\
cattle farming (beef rearing and fattening) & 6 \\
dairy farming (specialized dairying, beef production & 22 \\
as a joint output) & 89 \\
Total & \\
\hline
\end{tabular}

Bonnieux, 1986, p. 123. 
Table 2. Estimates of the factor share equation caefficients (symmetrical matrix)

\begin{tabular}{llccc}
\hline & & \multicolumn{3}{c}{ inputs } \\
equations & materials & capital & land & labour \\
\hline materials & 0.1371 & -0.0260 & -0.0302 & -0.0809 \\
& $(6.82)$ & $(2.68)$ & $(3.38)$ & $(3.42)$ \\
capital & & 0.0021 & 0.0204 & 0.0035 \\
& & $(0.18)$ & $(3.12)$ & $(0.32)$ \\
land & & 0.0127 & -0.0029 \\
& & & $(1.43)$ & $(0.25)$ \\
labour & & & & 0.0803 \\
& & & & $(2.45)$ \\
\hline
\end{tabular}

$t$ values are in parentheses.

Table. 3. Estimates of the factor share equation intercepts by regional category

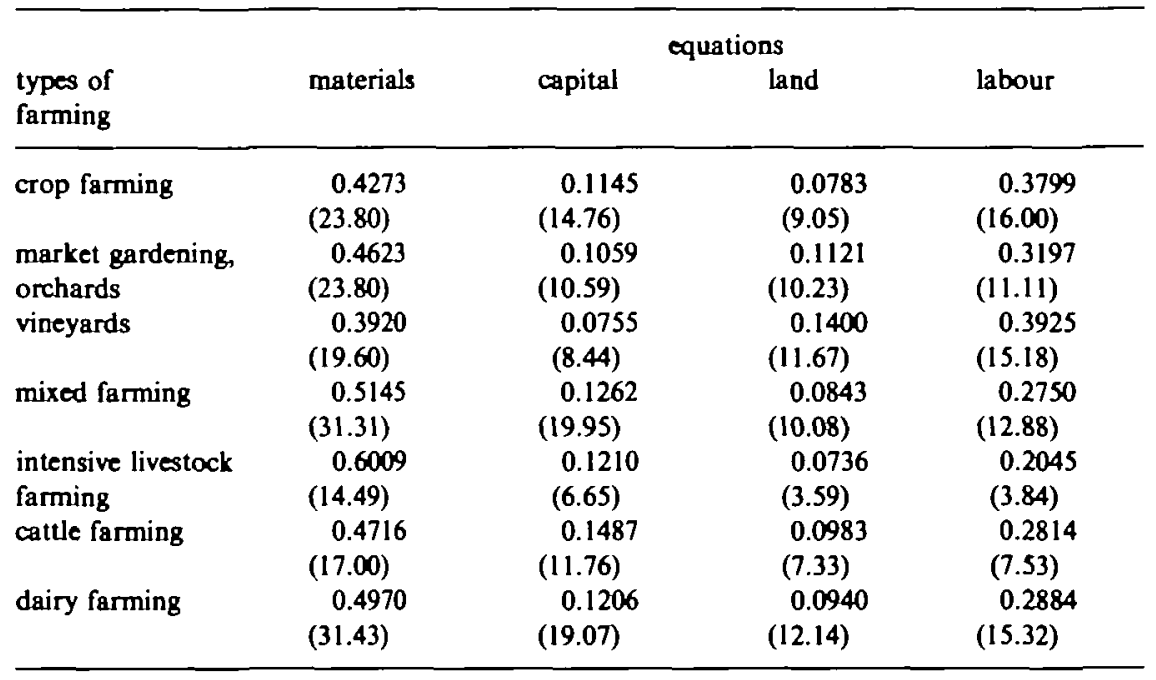

$t$ values are in parentheses.

Since monotonicity and convexity requirements are met at the mean values of the variables in each category and for all categories, the adjusted model is well-behaved for a large region in the input space. Therefore, it can be used to go into more detailed economic investigations. However, in order to increase the number of degrees of freedom, other specifications involving a smaller number of parameters, have been considered too.

The adjusted model with no dummies is well-behaved for the same points in the input space, but its statistical score is poorer, therefore the homogeneity hypothesis among region categories is rejected. ${ }^{2}$ Other specifications involving restrictions on parameters were tried. From Table 2, the t-statistic of the coefficients $b_{22}, b_{24}$ and $b_{34}$ is very small and the hypothesis that they 
equal zero cannot be rejected at a $10 \%$ level of significance. They imply the following restrictions between independent parameters:

$$
b_{22}=0, b_{12}+b_{23}=0 \text { and } b_{12}-b_{13}-b_{33}=0
$$

The log-likelihood of this restricted specification reaches 499.8 and is very close to the log-likelihood of the full specification. But the adjusted model is not well-behaved for three categories of regions (market gardening orchards, intensive livestock and cattle farming) and has not been considered any further.

Attempts to reduce the number of dummies did not succeed, either because the adjusted model is not well behaved for several categories, or because the log-likelihood is too small compared with that of the full model. Consequently the following derivations and comments are based upon the results reported in Tables 2 and 3.

\subsection{Allen and Hicksian elasticities}

Table 4 contains the estimated Allen elasticities of substitution by regional category. The underlying computation is too tedious to produce standard errors for elasticities, therefore these figures must be considered as orders of magnitude.

The technical substitutability of materials for all primary inputs is an interesting issue in itself. Allen elasticities are higher than unity implying strong substitutability. Otherwise it is not possible to draw conclusions regarding discrepancies between regional categories. Identifying feasible differences would need to break down materials so as to consider subaggregates like fertilizers or feed.

Capital and land are complements and there are some differences among categories. The value of the elasticity found for intensive livestock farming is

Table 4. Estimated Allen elasticities of substitution by regional category

\begin{tabular}{|c|c|c|c|c|c|c|}
\hline & \multicolumn{3}{|c|}{ materials- } & \multicolumn{2}{|c|}{ capital- } & \multirow{2}{*}{$\begin{array}{l}\text { land } \\
\text { labour }\end{array}$} \\
\hline & capital & land & labour & land & labour & \\
\hline $\begin{array}{l}\text { crop farming } \\
\text { market gardening }\end{array}$ & 2.28 & 3.06 & 2.09 & -2.87 & 0.52 & 0.52 \\
\hline orchards & 2.27 & 2.42 & 2.17 & -1.70 & 0.48 & 0.65 \\
\hline vineyards & 3.22 & 2.60 & 2.34 & -1.65 & 0.34 & 0.66 \\
\hline $\begin{array}{l}\text { mixed farming } \\
\text { intensive livestock }\end{array}$ & 1.97 & 2.56 & 2.66 & -2.07 & 0.48 & 0.54 \\
\hline farming & 2.41 & 3.69 & 3.70 & -8.53 & -0.98 & -1.06 \\
\hline cattle farming & 1.90 & 2.40 & 2.51 & -0.60 & 0.59 & 0.61 \\
\hline dairy farming & 1.99 & 2.42 & 2.67 & -1.47 & 0.52 & 0.61 \\
\hline
\end{tabular}

Elasticities are calculated at the mean values of the variables in each category. 
probably not appropriate but it reflects a technology using a very small amount of land and a large capital input in term of buildings. The complementarity relationship is stronger for crop farming. The technology used enables cultivation of a large acreage per worker and requires a high machinery input.

Intensive livestock farming excluded, labour is a substitute for capital and land. Allen elasticity does not vary very much across regional categories. These findings are consistent with previous knowledge of long term development pattern of the agricultural sector. Intensive livestock farming does not benefit from strong substitution possibilities as other types of farming do. The only exception is between materials and primary inputs. An example of such substitution possibilities is the substitution of feed purchased from offfarm source to feed produced on farm.

Previous results must be considered as long run elasticities and are not easily comparable with empirical findings of studies based upon time series. Moreover, comparisons are hampered by the substantial differences in the precise definition of inputs.

The estimation of a translog cost function from 1959-84 time series with exactly the same inputs (Guyomard 1988: 211) provides results which are consistent with ours. Substitutability is found for all pairs of inputs except capital-land for which the Allen elasticity is not significantly different from zero. Let us note that the capital-materials elasticity has increased over time. Based upon the estimation of a total cost function with the same four inputs, Capalbo (1985) finds that factors are pairwise substitutes for US agriculture. For Canadian agriculture Lopez (1980) reaches the same results.

Binswanger's analysis (1974) is closest to our study because he has pooled four cross-sections of 39 regions which are distributed among five categories. But he considered five inputs (land, labour, machinery, fertilizers and others) so it is difficult to compare his findings with ours. However, he found a complementary between fertilizers and labour that could be considered as inconsistent with the substitutability between materials and labour which was found. Fertilizers are only a component of materials and that can explain this difference but otherwise Binswanger's result has been contradicted by other analyses based upon time series. It is more common to find a substitutability between fertilizers and labour (Boyle 1981; Kako 1978; Lopez 1980; Ray 1982).

Table 5 gives price elasticities of input demands. They are own-price elastic since figures vary from -0.99 for capital to -1.18 for materials. Primary input demands are elastic to material price changes. Other crosselasticities are smaller than unity. Capital-price and land-price have a small influence on labour demand.

The range of price-elasticity estimates published in the literature is quite large. High values for own-price elasticity of capital (Binswanger 1974; Lopez 1984) or labour (Binswanger 1974, Ray 1982) can be quoted. Few 
Table S. Hicksian elasticities of inputs with respect to price changes

\begin{tabular}{lcrrr}
\hline quantities & materials & capital & \multicolumn{1}{c}{ prices } \\
& & \multicolumn{1}{c}{ land } & labour \\
\hline materials & -1.18 & 0.24 & 0.24 & 0.70 \\
capital & 1.00 & -0.99 & -0.17 & 0.16 \\
land & 1.17 & -0.20 & -1.17 & 0.20 \\
labour & 1.03 & 0.06 & 0.06 & -1.14 \\
\hline
\end{tabular}

Elasticities are evaluated at the mean value of the variables for categories.

authors used materials as a single input, among them Capalbo (1985) found own-price elasticity estimates smaller than unity, however higher values can be easily found for various components of materials, for instance for nitrogen (Boyle, 1981), seeds and chemicals (Batista 1985). Besides Higgins (1986) obtained smaller values for the own-price elasticity of Hicksian demand for concentrate and bulky feed, and fertilizer. But his analysis is not really comparable with ours because he considered livestock, capital, family labour and land as fixed inputs. Therefore elasticities of Table 5 can be considered as being consistent with results published elsewhere.

\subsection{Input separability}

Berndt and Christensen (1973b) stated that weak separability, the existence of a consistent aggregate of inputs and certain equality restrictions on the Allen elasticities of substitution are equivalent. For the four input case, $X_{t}$ and $X_{j}, X_{k}, X_{t}$ are weakly separable if and only if:

$$
s_{i j}=s_{i k}=s_{i l}
$$

When the production function is a translog one, condition (5) can be replaced by an equivalent condition involving input shares and parameters since:

$$
s_{i j}-s_{i k}=0 \leftrightarrow b_{i j} M_{k}-b_{i k} M_{j}=0
$$

Therefore, there are three linear restrictions, two of which are independent. In order to perform a local test of weak separability, it is enough to consider simultaneously the t-tests connected with these restrictions (Humphrey and Moroney 1975). When it is performed at the sample mean it is equivalent with a test described by Denny and Fuss (1977). Table 6 describes the result of this latter one in order to consider weak separability of every input from the remaining three.

Therefore, for every $i, X_{i}$ and $X_{j}, X_{k}, X_{l}$ are not weakly separable. Input separability being rejected, it is not consistent to aggregate primary inputs for instance in order to consider value-added. This local test has been performed for each regional category and the same result was found. Moreover it would be globally true if condition (4) is met since $b_{11}, b_{12}$ and 
Table 6. Probabilities of rejecting weak separability

\begin{tabular}{lll}
\hline separability of & nul hypotheses & rejocting probabilities \\
\hline I materials & $s_{12}=s_{13}$ & 0.46 \\
& $s_{12}=s_{14}$ & 0.14 \\
$s_{13}=s_{14}$ & 0.34 \\
& $s_{12}=s_{23}$ & 1.00 \\
& $s_{12}=s_{24}$ & 0.84 \\
& $s_{23}=s_{24}$ & 0.98 \\
3 land & $s_{13}=s_{23}$ & 1.00 \\
& $s_{13}=s_{34}$ & 0.72 \\
& $s_{23}=s_{34}$ & 0.98 \\
4 labour & $s_{14}=s_{24}$ & 0.96 \\
& $s_{14}=s_{34}$ & 0.76 \\
& $s_{24}=s_{34}$ & 0.29 \\
\hline
\end{tabular}

$b_{13}$ estimates are significantly different from zero at the $.05 \%$ level. To make this point clear it is enough to apply condition (6) to every input combination.

\subsection{Breaking-down labour input}

So far, labour has been considered as a single input. The aggregate is obtained by adding self-employed labour and hired labour; self employed being broken down between farm operator labour and unpaid family labour. Basic statistics use a standard unit of labour which relies upon a classification in terms of number of hours worked. They proceed by simple summing across labour classifications using a unitary weight irrespective of occupation. ${ }^{3}$

Breaking-down labour into two categories, self-employed and hired is now being considered. Using the system of factor share equations a five input production function was estimated. The adjusted model is not well-behaved for three regional categories (vineyards, intensive livestock and cattle farming). For the others a complementarity relationship between the two types of labour is found, the estimated Allen elasticity of substitution varies from -.47 for dairy farming to -1.38 for crop farming. For the average of all categories it equals -.80 . This result is consistent with Lopez's findings (1984) for Canadian agriculture. Brown and Christensen (1981) report values of Allen elasticity for US agriculture. They find a weak substitution from 1947 up to 1953 and a complementary relationship in later years. Allen elasticity decreases from -0.42 in 1954 to -2.65 in 1974 .

Regional figures are not reliable enough to infer more results regarding labour. Since there are some indications that the distribution of labour by activity varies immensely according to types of agricultural enterprises, more specific studies would be necessary to go forward. A research based on microdata and run by type of farming, would probably be a good way to tackle this problem. 


\section{Concluding comments}

A full static equilibrium model, using cross-regional data, has been estimated for French agriculture. The translog specification with dummies reveals enough flexibility to take regional differences into account. Primal approach has performed well, despite its limitations due to difficulties in estimating input services and to simultaneity bias.

A number of conclusions emerge concerning technology and input demand. Results have been obtained for the four input case (materials, capital, land and labour). Input separability is rejected, so it is wrong to consider an aggregate such as value added. Inputs are pairwise substitutes, except land and capital which are complements. The empirical analysis has produced reasonable factor elasticity of substitution and input elasticity estimates. They must be viewed as long term elasticities, which explains some high values. More specifically a strong substitution between materials and primary inputs has been found. Input demands are own-price elastic. Moreover, the demand for primary inputs is materials price elastic.

The breaking-down of labour between self employed and hired labour, leads to the interesting conclusion that these types of labour are complements. But the results deduced from a five input production function are weaker. More generally it seems difficult to handle many factors with such a specification. It must be considered as a way to deduce general conclusions about technology. Taking into account inputs at a disaggregated level would need maintained hypotheses on separability in order to run a step by step estimation process.

\section{APPENDIX}

The Allen elasticity of substitution (Allen, 1938: 504-505) between inputs $X_{i}$ and $X_{j}$ is given by:

$$
s_{i j}=\left(Y / X_{i} X_{j}\right)\left(\left|F_{i j} /\right| F \mid\right)-\infty<s_{i j}<\infty \quad i, j=1, \ldots, I .
$$

where $|F|$ is the determinant of the bordered Hessian matrix $F$ and $\left|F_{y}\right|$ is the cofactor of $\partial^{2} Y / \partial X_{i} \partial X_{j}$. Using a procedure set up by Berndt and Christensen (1973a) for the three input case we consider the $(I+1)$ order symmetric matrix:

$$
G=\left[\begin{array}{cccc}
0 & M_{1} & M_{2} & M_{I} \\
M_{1} & b_{11}+M_{1}^{2}-M_{1} & b_{12}+M_{1} M_{2} & b_{1 I}+M_{1} M_{I} \\
M_{2} & b_{12}+M_{1} M_{2} & b_{22}+M_{2}^{2}-M_{2} & b_{2 I}+M_{2} M_{I} \\
\vdots & \vdots & \vdots & \vdots \\
M_{1} & b_{1 I}+M_{1} M_{I} & b_{2 I}+M_{2} M_{I} & b_{I I}+M_{I}^{2}-M_{I}
\end{array}\right]
$$


and

$$
\begin{array}{ll}
s_{i i}=\left|G_{i i}\right| /|G| & i=1 \ldots I \\
s_{i j}=\left|G_{i j}\right| /|G| & i, j=1 \ldots I \quad i \neq j
\end{array}
$$

where $|G|$ is the determinant of $G,\left|G_{i i}\right|$ is the cofactor of the element $b_{i l}+M_{i}^{2}-M_{i}$ and $\left|G_{i j}\right|$ the cofactor of $b_{i j}+M_{i} M_{j}$.

Therefore the computation of the matrix

$$
S=\left(s_{i j}\right) i, j=1 \ldots I .
$$

requires to invert the matrix $G$ and to take out the suitable matrix of order equal to $I$. If the matrix $S$ is negative semi-definite then convexity is met for share values for which it has been calculated. Monotonicity and convexity must be viewed as local properties of the adjusted model. This check is usually done for points of a particular interest in the input space.

\section{NOTES}

1. There are $I-1$ independent $a_{t}$ plus $(I-1)(K-1)$ independent $a_{a k}$. The matrix of general term $b_{y}$ is symetric so it has $I(I-1) / 2+I$ different terms, which are subject to $l$ independent restrictions.

2. The log-likelihood reaches 465.9 only. So the text statistic of the likelihood ratio equals $\mathbf{6 8 . 0}$ which has to be compared with 37.2, critical value of the chi-square with 18 degrees of freedom for a confidence level of 99.5 .

3. This procedure would be convincing if the different types of labour were perfect substitutes. As quoted by Lopez (1984) such an essumption is highly unrealistic mainly because operator and hired labour perform rather different activities. Generally managerial activity is an important component of operators' work while wage earners are mainly farm labourers. However, the number of professionals and skilled wage-earners reaches $38 \%$ of the total (Colliez 1984); moreover, this percentage is higher for younger than for older people and will increase in the future.

\section{REFERENCES}

Allen, R.G.D. (1938). Mathematical Analysis for Economists. London: McGraw-Hill.

Batista, J.C. (1985). Regional opportunity cost of producing milk and the agricultural production effects of alternative spatial pricing policies in dairying. Doctoral Dissertation, Faculty of the Graduate School of Cornell University.

Berndt, E.R. and Christensen, L.R. (1973a). The translog function and the substitution of equipment, structures and labor in US manufacturing 1929-68. Joumal of Econometrics 1: 81-114.

- (1973b). The internal structure of functional relationships: separability substitution and aggregation. The Review of Economic Studies 40: 403-409.

Binswanger, H.P. (1974). A cost function approach to the measurement of elasticities of factor demand and elasticities of substitutions. American Journal of Agricultural Economics 56: 377-386.

Bonnieux, F. (1986). Etude économétrique des disparités de l'agriculture franfaise sur la base de donntes dipartementales. I.N.R.A., Economie et Sociologie Rurales, Rennes. 
Boyle, G. (1981). Input substitution and tochnical change in Irish agriculture. Economic and Social Review 12: 149-161.

Brown, R.S. and Christensen, L.R. (1981). Estimating elasticities of substitution in a model of partial static equilibrium: an application to US agriculture, 1947 to 1974. In E.R. Berndt and B.C. Field (ed.) Modeling and measuring natural resource substitution. Cambridge, Mass.: MIT Press.

Capalbo, S.M. (1985). A comparison of econometric models of US agricultural productivity and technology structure. Discussion Paper Series, RR85-05, Resources for the Future, Washington.

Colliez, J.P. (1984). Les salariés agricoles permanents, leur rémunération en octobre 1982. Collections de Statistique Agricole $\mathrm{n}^{\circ} 228$, Ministère de l'Agriculture, Paris.

Denny, M. and Fuss, M. (1977). The use of approximation analysis to test for separability and the existence of consistent aggregates. American Economic Review 67: 404-418.

Diewert, W.E. (1974). Application of duality theory. In M.D. Intriligator and D.A. Kendrick (ed.) Frontiers of Quantitative Economics, vol. 2. North-Holland Publishing Company: Amsterdam.

Guyomard, H. (1988). Investissement et choix techniques du secteur agricole français: étude économétrique. Doctoral Dissertation, Université de Rennes, 1988.

Higgins, J. (1986). Input demand and output supply on Irish farms - a micro-economic approach. European Review of Agricultural Economics 13: 477-493.

Humphrey, D.B. and Moroney, J.R. (1975). Substitution among capital, labor and national resource products in American manufacturing. Journal of Political Economy 83: 57-82.

Kako, T. (1978). Decomposition analysis of derived demand for factor inputs: the case of rice production in Japan. American Journal of Agricultural Economics 60: 628-635.

Lopez, R.E. (1980). The structure of production and the derived demand for inputs in Canadian agriculture. American Journal of Agricultural Economics 62: 38-45.

- (1984). Estimating substitution and expansion effects using a profit function framework. American Journal of Agricultural Economics 66: 358-367.

Mergos, G.J. (1987). Resource structure in Greek agriculture: a multi-output profit function approach. Paper presented in the 5th Congress of the European Association of Agricultural Economists, Balaton, Hungary.

Mergos, G.J. and Yotopoulos, P.A. (1988). Demand for feed inputs in the Greek livestock sector. Europeon Review of Agricultural Economics 15: 1-17.

Ray, S.C. (1982). A translog cost function analysis of US agriculture, 1939-77. American Journal of Agricultural Economics 64: 490- 498.

S.C.E.E.S. (1981). Estimation des amortissements départementaux de l'agriculture. Synthèses statistiques. Comptes et revenus n* 35, Ministère de l'Agriculture, Paris.

\section{F. Bonnieux}

INRA

Economie et sociologie rurales

65, rue de St-Brienc

35042 Rennes

France 
